\title{
Non-instrumental clinical monitoring does not guarantee an adequate course of general anesthesia. A prospective clinical study
}

\author{
Katarzyna Szostakiewicz, Zbigniew Rybicki, Dariusz Tomaszewski
}

\begin{abstract}
Background. Clinical monitoring is the most common method of adjusting the appropriate level of general anesthesia. However, episodes of intraoperative awareness (AWR) are still reported, suggesting that clinical observations may not be sufficient in some cases. The objective of this study was to compare the efficacy of clinical and instrumental neuromonitoring with auditory evoked potentials (AEP) in an intraoperative analysis of the proper level of general anesthesia. Methods. Patients scheduled for elective surgery were randomly divided into two groups. Subjects in the first group underwent intravenous, in the second group volatile anesthesia. The adequacy of anesthesia was analyzed using clinical parameters. All the participants were instrumentally monitored with the autoregressive AEP index (AAI). After the anesthesia, patients filled out a questionnaire on possible AWR.

Results. Data of 208 patients (87 in the first, and 121 in the second group) were analyzed. Before surgery there were no changes in AAI values between groups ( $80 \mathrm{vs.} 78, P=0.5192$ ). The mean values of clinical parameters changed, but five minutes after the nociceptive stimuli. The mean values of AAI at analyzed time points were specific for general anesthesia. In patients under intravenous anesthesia, we found more episodes of too low $(46 / 608 \mathrm{vs} .15 / 847, P<0.000)$ anesthesia. One case of AWR was found in the TIVA group.

Conclusions. AAl index is good indicator of patients' level of consciousness during general anesthesia. Standard clinical monitoring provides appropriate level of the procedure. However, it is insufficient during TIVA and does not prevent episodes of AWR.
\end{abstract}

Key words: volatile anesthesia, total intravenous anesthesia, intraoperative awareness, neuromonitoring, auditory evoked potential, AAl index

Received: September 25, 2017; Accepted: March 2, 2018; Available online: March 21, 2018

https://doi.org/10.5507/bp.2018.008

Department of Anesthesiology and Intensive Therapy, Military Institute of Medicine, 128 Szaserow Str., 04141 Warsaw, Poland Corresponding author: Dariusz Tomaszewski, e-mail:dtomaszewski@wim.mil.pl

\section{INTRODUCTION}

The incidence of intraoperative awareness in patients undergoing surgical procedures under general anesthesia (GA) varies between 0.1-0.2 and 2.1-9.1 pro mille; a higher incidence is observed in cardiac surgery patients, women after caesarean sections, victims of multiple trauma as well as children. The difficulties in maintaining the proper level of general anesthesia arise from complex mechanisms involved in the physiology of dreams and consciousness ${ }^{1,2}$, the multidirectional (including cardiodepressive) mechanisms of action of anesthetics ${ }^{3,4}$, differences in pharmacokinetics and pharmacodynamics of anesthetics, genetic variability of patients ${ }^{5,6}$ as well as from experience of the anesthesiologist. Implicit and explicit recalls after procedure, resulting from too low level of anesthesia, may cause posttraumatic stress disorder (PTSD) and both acute and chronic mental disorders. These problems can affect from $4 \%$ to $70 \%$ of patients up to two years after the traumatic event ${ }^{5,7-11}$. On the other hand, too deep a level of anesthesia can increase the incidence of postoperative cognitive decline, postoperative delirium, time of hospitalization and accelerate the onset of senile dementia ${ }^{12-15}$. Analysis of the proper level of an- esthesia is based on assessment of clinical parameters, autonomic and somatic reflexes ${ }^{16}$. However, clinical parameters are not reliable indicators of adequate level of general anesthesia ${ }^{5,7,17-22}$.

Currently, the role of instrumental monitoring in analysis of proper level of anesthesia is increasing. The mode of action of all these instruments relies on analysis of changes in brain functions due to anesthetics ${ }^{23}$. The most common is analysis of spontaneous electroencephalogram (EEG) and/or evoked potentials. Instrumental neuromonitoring was recommended by the international associations of anesthesiologists ${ }^{24,25}$. It was shown that monitoring of brain functions decreases the possibility of both intraoperative awareness and too deep a level of anesthesia ${ }^{12,14,15}$. The costs of hospitalization and the incidence of postoperative nausea and vomiting were also decreased. Moreover, the patients' postoperative level of consciousness was better ${ }^{14,26,27}$.

The objective of the study was (1) to compare the value of basic clinical parameters and simultaneously recorded AEP for analysis of the depth of both total intravenous and volatile anesthesia, and (2) incidence of intraoperative awareness. 


\section{METHODS}

The Ethics Committee of the Military Institute of Medicine (Warsaw, Poland) reviewed and approved this clinical investigation, which was registered at clinicaltrials. gov (NCT0333169).

A written, informed consent was obtained from all the subjects.

This project was planned as a prospective study. After commenced of the study its design was not modified.

The participants were hospitalized at the Department of Otolaryngology and at the Department of Neurosurgery of the Military Institute of Medicine, Warsaw, Poland. The inclusive criteria were (1) patients between 18 and 61 years old, (2) with preoperative health status I or II grade according to the American Society of Anesthesiologists (ASA) score, (3) scheduled for otorhinolaryngological (ear, nose, throat; ENT) procedures or discectomy.

The patients suffering from (1) hearing problems or tinnitus, (2) chronic inflammatory process of the ear, (3) epilepsy, (4) mental disorders, and (5) pregnancy were excluded from the study.

Two hundred and eight patients were assessed for eligibility. The participants were randomly (by flipping a coin) divided into one of the two groups, depending on the planned type of anesthesia:

1. Total intravenous anesthesia (TIVA),

2. Volatile anesthesia (VOL).

Benzodiazepines were not administered as premedication drugs.

In all the participants, continuous electrocardiogram, non-invasive blood pressure, pulse oximetry and end-tidal concentration of carbon dioxide were monitored.

Propofol as an induction agent of general anesthesia, fentanyl or remifentanil as an analgesic, and cisatracurium or vecuronium bromide as myorelaxant were administered. Anesthesia was conducted with continuous infusion of propofol according to the De Grood scheme ${ }^{28}$ (TIVA group) or sevoflurane (VOL group) with end-tidal concentration of volatile anesthetic between 0.8 and 1.2 minimum alveolar concentration (MAC). The patients were ventilated with a mixture of air and oxygen, with $\mathrm{FiO}_{2} 0.5$, and etCO ${ }_{2}$ between 30 and $40 \mathrm{mmHg}$. The intraoperative administration of anesthetics was modified according to patients' demands. The hemodynamic stability was maintained by optimization of the level of anesthesia. When the systemic blood pressure decreased below $30 \%$ in comparison to preoperative values, ephedrine hydrochloride was administered intravenously. Episodes of bradycardia (45/min and lower) were treated with intravenous administration of atropine sulphate. After the surgery and reversal of neuromuscular blockade the patients were extubated.

In all the participants an A-line ARX index (AAI) was continuously monitored with AEP Monitor/2 version 1.6 Danmeter. The AAI is calculated from the middlelatency auditory evoked potentials waves, extracted from electroencephalographic signal using an autoregressive model with an exogenous input (ARX). The electrodes were placed on the forehead and in the region mastoid bone, and then the impedance of the electrodes was checked, the impedance of the electrodes was not greater than $5 \mathrm{k} \Omega$.

Intraoperatively, auditory evoked potentials (AEP) with AAI were recorded every $1.1 \mathrm{~s}$. Electroencephalogram with burst suppression (BS) analysis was recorded and updated every $0.5 \mathrm{~s}$. Recorded data were blinded for anesthesiologists, so were not used for analysis of level of anesthesia during surgery. The alarm limits of recorded parameters were adjusted to correct the technical interferences.

Analyzed data were recorded in the following time points:

T1 - after premedication, before the onset of anesthesia, $\mathrm{T} 2$ - during the induction of anesthesia (30 s after intra-

venous administration of hypnotic dose of propofol), T3 - just before the endotracheal intubation,

T4 - 60 seconds after the endotracheal intubation,

T5 - 5 minutes after the endotracheal intubation,

T6 - at the beginning of surgery - just after skin incision, T7-T12 - every 5 min during the surgery and anesthesia, T13 - at the end of the surgery (after skin closure),

T14 - before the extubation,

T15 - just after the extubation,

T16 - just after the return of consciousness of the patient.

After the surgery the participants were asked to answer the questions about the possibility of intraoperative awareness. This questionnaire was based on work of Brice ${ }^{29}$. The answers of the patients were classified according to Michigan Awareness Classification score ${ }^{30}$. Such score was shown in Table 1. This visit took place not earlier than $24 \mathrm{~h}$ after the anesthesia.

\section{Statistical analysis}

Collected data were archived with Microsoft Excel 2013 software. The data were analyzed using R statistical software (R Core Team R: A language and environment for statistical computing. $R$ foundation for statistical computing, Vienna, Austria 2014. http://www.R-project.org/).

The analysis of the data was begun by using the Shapiro-Wilk test to determine whether they were normally distributed. Demographic data were analyzed with descriptive statistics.

Table 1. Michigan Awareness Classification Score.

\begin{tabular}{ll}
\hline Class 0 & No awareness \\
Class 1 & Isolated auditory perceptions \\
Class 2 & $\begin{array}{l}\text { Tactile perceptions (e.g. surgical manipulation } \\
\text { or endotracheal tube }\end{array}$ \\
Class 3 & Pain \\
Class 4 & $\begin{array}{l}\text { Paralysis (e.g. feeling one cannot move, speak, } \\
\text { or breathe) }\end{array}$ \\
Class 5 & Paralysis and pain \\
\hline
\end{tabular}

An additional designator of " $\mathrm{D}$ " for distress is included for patient reports of fear, anxiety, suffocation, sense of doom, sense of impending death, etc. 
The differences between the two groups were analyzed with a chi square test, Student's t test and Mann-Whitney $\mathrm{U}$ test. Mean values of data in respective time points between two groups were analyzed with the Mann-Whitney $\mathrm{U}$ test, and inside each group with Wilcoxon signed rank test.

$P<0.05$ was considered statistically significant.

\section{RESULTS}

Finally, data from 208 patients were analyzed. The characteristics of the participants are shown in Table 2. There were 25 ENT procedures, 27 discectomies in sacrolumbar, and 35 discectomies in the cervical region of the vertebral column in the TIVA group. In the VOL group it was 24,52 , and 45 procedures, respectively.

There were no differences between groups in duration of anesthesia; mean time was $124 \pm 40 \mathrm{~min}$ in TIVA, and $113 \pm 30 \mathrm{~min}$ in VOL group. The time between the end of surgery and patient's extubation was also similar in both groups, it was 9.6 $\pm 3.1 \mathrm{~min}$ in TIVA and $9.4 \pm 2.9 \mathrm{~min}$. The details of analyzed data (heart rate /HR/, systolic arterial pressure /SAP/, mean arterial pressure /MAP/, diastolic

Table 2. The characteristics of the participants.

\begin{tabular}{lccc}
\hline & TIVA group & VOL group & $P$ \\
\hline Patients, n (men/women) & 87 & 121 & 0.14 \\
Men / women, n & $50 / 37$ & $57 / 64$ & \\
Age, years (median, Q1-Q3) & $51(40-56)$ & $44(37-53)$ & 0.01 \\
ASA status (I/II) & $29 / 58$ & $58 / 63$ & \\
BMI (median, Q1-Q3) & $25.5(23-29)$ & $27(24-29)$ & 0.82 \\
\hline
\end{tabular}

ASA - American Society of Anesthesiologists's preoperative health status classification, BMI - body mass index. arterial pressure /DAP/, AAI, BS) in consecutive time points are presented in Table 3 .

AAI readings above 25 (max. 51) in TIVA group were $46 / 608(8 \%)$ of recorded values during conduction of anesthesia, in comparison to $15 / 847$ (2\%) in VOL group $(P<0.0000)$. In TIVA group we noted higher incidence of burst suppression episodes $(29 / 608,5 \%)$, in comparison to VOL group (49/847,6\%), but such difference was not statistically significant $(P=0.3963)$. The changes in AAI during anesthesia were shown in Fig. 1.

We found one case of intraoperative awareness. This case was $0.48 \%$ of the sample and $1.15 \%$ of patients in the TIVA group. Amongst the patients under volatile anesthesia no cases of intraoperative awareness were noted.

The incidence of dreaming during general anesthesia was also analyzed. Mean time between the end of anesthesia and collecting the questionnaire was $30 \mathrm{~h}$.

In both groups, the percent of patients reported dreaming during anesthesia was similar (Table 4).

\section{DISCUSSION}

This is the first paper where in 208 patients the whole course of general anesthesia at 16 time points was analyzed and intravenous and volatile anesthesia were compared. We found, that clinical monitoring alone does not protect from both too shallow and too deep episodes of general anesthesia.

Our results and data from other authors are similar.

The mean values of AAI before the surgery were comparable in both groups. It indicates, that the level of preoperative sedation in TIVA and VOL groups was comparable.

During induction of anesthesia rapid decrease of AAI was observed. The data of other authors also indicated

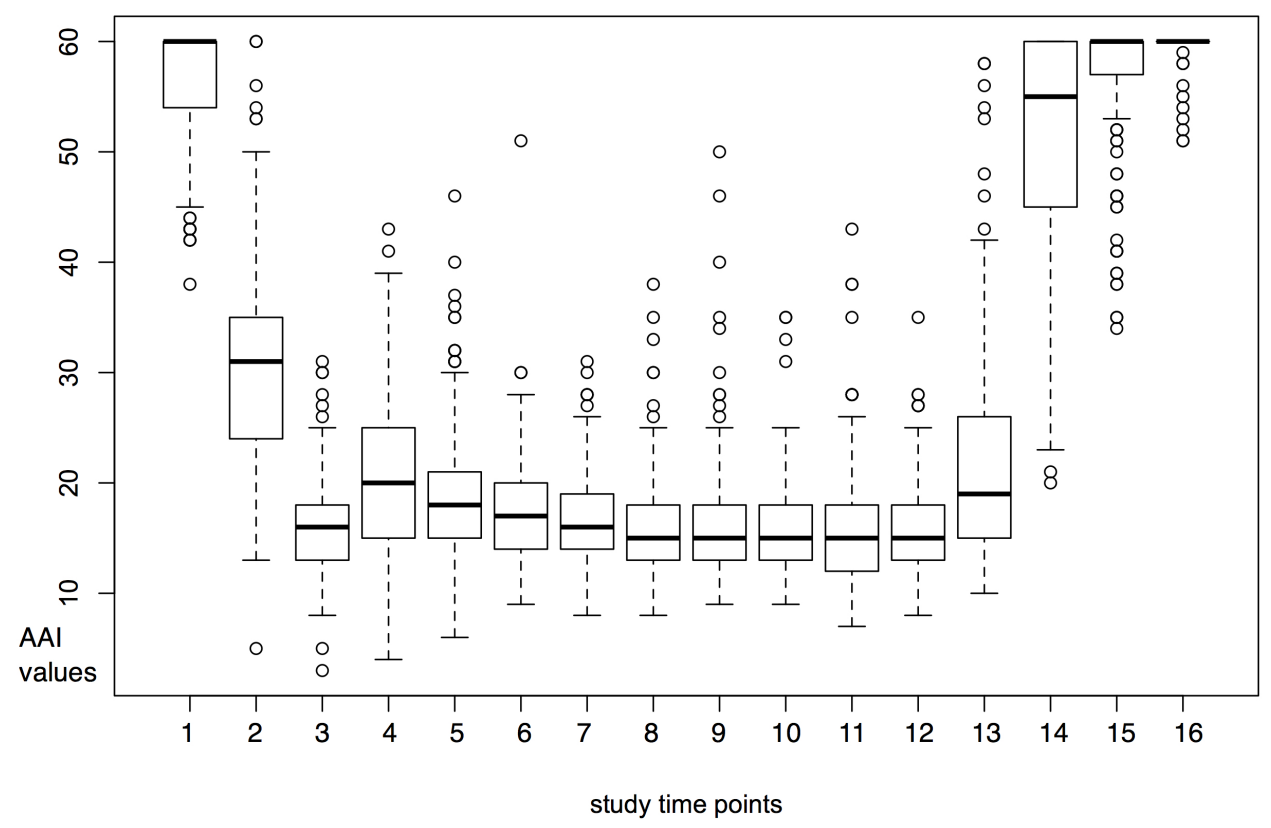

Fig. 1. Changes of AAI values in study population. 


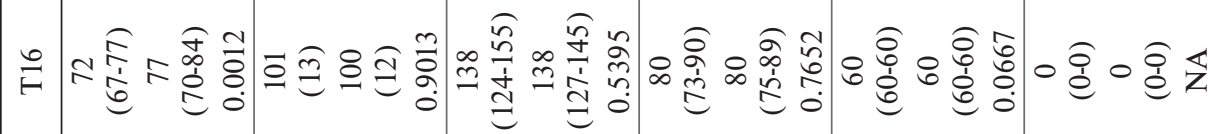

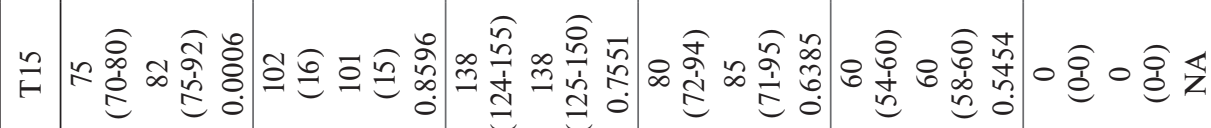

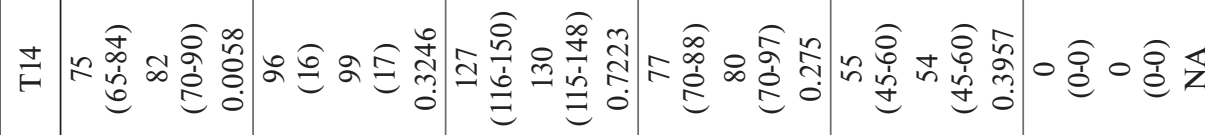

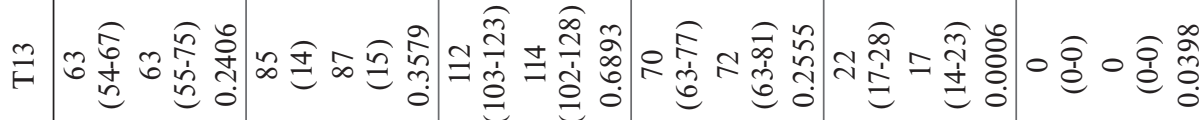

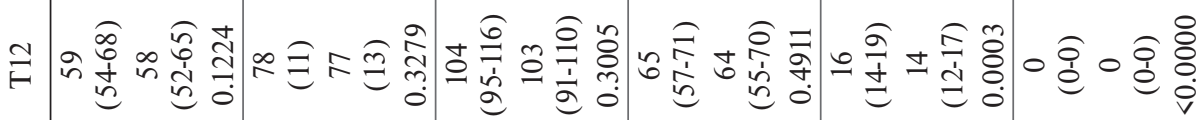

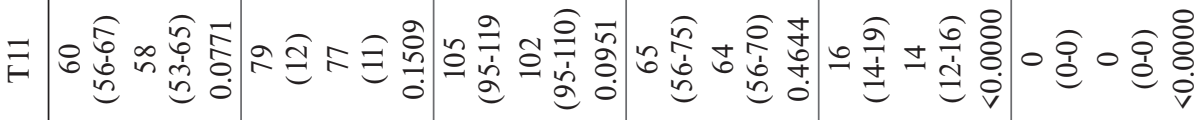

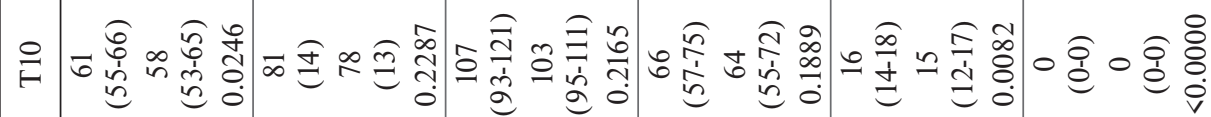

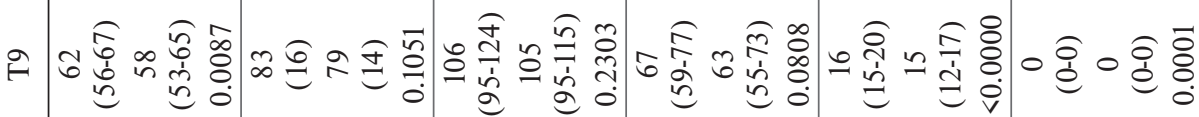

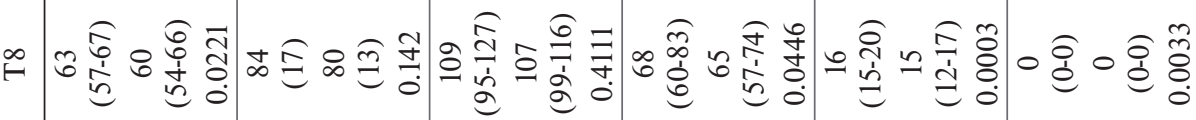

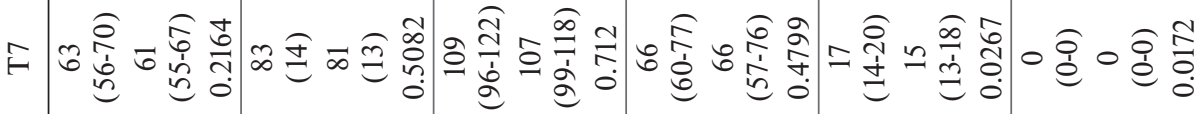

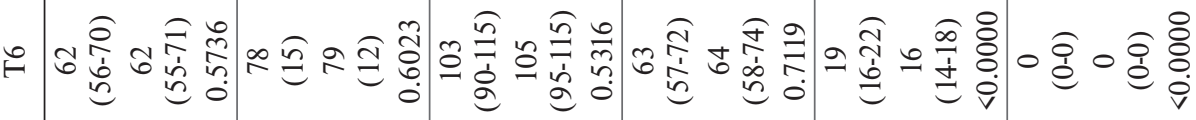

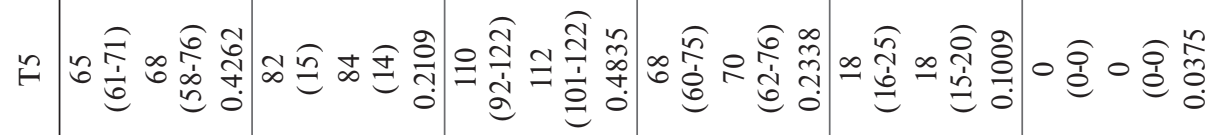

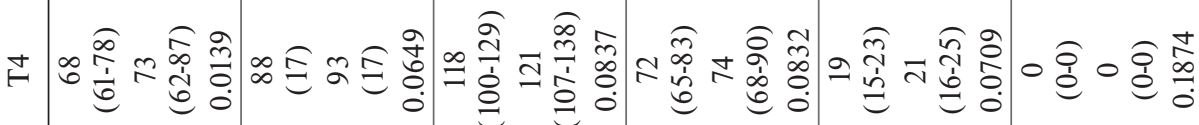

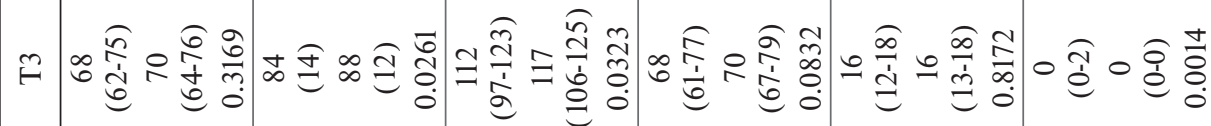

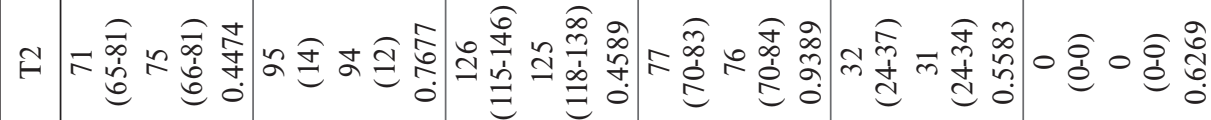

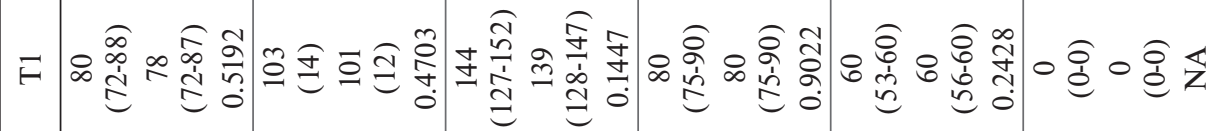

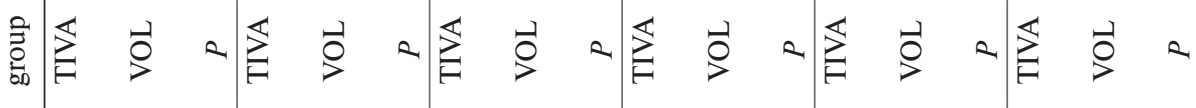

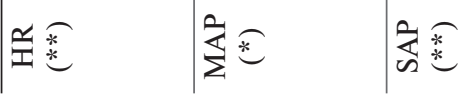

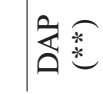
安意的䨔

产垔 竞. 뒁 采要 秀要莺 E 11 密它的言

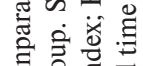
임. ․․․

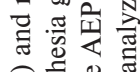

在氧 政 这 편흉워 훙요 
Table 4. Intraoperative dreaming (based on the post anesthesia questionnaire survey).

\begin{tabular}{lll}
\hline "Dream" & TIVA group & VOL group \\
\hline Total & $12 / 87(13.8 \%)$ & $16 / 121(13.22 \%)$ \\
Positive / nice & $9 / 87(10.34 \%)$ & $15 / 121(12.4 \%)$ \\
Negative / unpleasant / bad & $9 / 87(10.34 \%)$ & $15 / 121(12.4 \%)$ \\
\hline
\end{tabular}

TIVA group - totally intravenous anesthesia group, VOL - volatile anesthesia group.

that AAI was one of the most sensitive variables of level of consciousness $^{21,31-36}$. The observations of others ${ }^{37-39}$ showed the higher sensitivity of auditory evoked potentials in comparison to spontaneous electroencephalogram in evaluating the changes of consciousness. During induction of anesthesia, together with decrease in AAI, in both groups also heart rate and systemic blood pressure decreased. The observations of Freo et al. were similar ${ }^{27}$. During induction of anesthesia, the AAI was always decreased; however other clinical parameters varied. Nishiyama et al. observed decrease in systolic blood pressure and AAI only; the frequency of heart rate was increased ${ }^{39}$. In contrast, Milne et al. noted decrease of mean blood pressure and AAI, without changes in heart rhythm ${ }^{38}$. Weber et al., in their study on the utility of AAI in analysis of the level of anesthesia found significantly decreased values of mean blood pressure, increased heart rate and decreased AAI $\left(\right.$ ref. $\left.^{40}\right)$.

Before the endotracheal intubation, mean values of AAI in both groups were 16 , which is characteristic for a deep level of anesthesia. This observation was confirmed by EEG analysis, and the highest observed number of burst suppression. It should ensure the adequate protection during endotracheal intubation. However, during intubation, both systemic blood pressure as well as AAI quickly increased in both groups. Only heart rate in the TIVA group did not change. The increase of AAI was significant in both groups, but mean index values did not exceed the limits of proper surgical anesthesia. It confirms the observations of Ekman et al. ${ }^{35}$ that low records of neuromonitoring did not guarantee the absence of patient's response to endotracheal intubation. Probably this was the result of reflex reaction at the level of the brainstem and hypothalamus. In the study of Allahyary et al. ${ }^{41}$ the increased values of hemodynamic parameters during intubation were correlated with decreased AAI, probably as a result of increased concentration of volatile anesthetic. Chen et al. ${ }^{42}$ found that the number of unwanted patients' reactions to intubation was reduced when the neuromonitoring with AAI was used during anesthesia.

During the conduction of anesthesia the changes of AAI were similar in both groups. After the intubation, the values of AAI progressively decreased, until its final stabilization within the limits of surgical anesthesia was observed. However, there were more AAI readings above 25 in the TIVA group, in comparison to VOL group. The increase of AAI value above 25 - 30 may indicate the possibility of intraoperative awareness. AAI was more stable in VOL group. However, lower values of AAI during volatile anesthesia may indicate that volatile anesthetics were overdosed ${ }^{27}$. Intraoperative monitoring of level of anesthesia can reduce the consequences of neurotoxicity of anesthetics ${ }^{14,15,43,44}$.

Clinical parameters during conduction of anesthesia varied, probably as a result of administered doses of anesthetics. General anesthesia in the TIVA group was less stable; its level varied from very deep to much shallower. Although during intravenous anesthesia all drugs are administered continuously, the speed of infusion depended on the clinical status of the patients. The higher stability of volatile anesthesia probably arises from the monitoring of end-tidal concentration of volatile anesthetic. Good correlation between AAI and concentration of both volatile $\mathrm{e}^{32,39,41,45,46}$ and intravenous anesthetics ${ }^{21,37,38,47}$ during anesthesia was observed. At the end of surgery, together with decreasing concentration of volatile anesthetics, both AAI values and clinical parameters increased till the reversal of anesthesia. The dynamics of these changes were similar in both groups. There were no differences in mean values of SAP, DAP and MAP between TIVA and VOL groups; the heart rate was higher in VOL, in comparison to TIVA group. Mean values of AAI after reversal of anesthesia was 60 in both groups, similarly to values observed before the induction of anesthesia. Because there was a good correlation between the level of conscience and AAI, use of neuromonitoring during anesthesia makes the prediction of the time of recovery over anesthesia more simple s9,41,46,47 $^{3}$ and can reduce period between end of anesthesia and extubation $^{22,27,31,48,49}$.

The episodes of intraoperative awareness were surveyed using a questionnaire based on the work of Brice ${ }^{29}$, because of its efficacy and large number of studies ${ }^{50}$.

The highest detection of intraoperative awareness was noted when the questionnaire survey was carried out between 14 and 30 days after surgery ${ }^{50,51}$. Sebel et al. ${ }^{7}$ and Mashour et al. ${ }^{50}$ found a higher detection of intraoperative awareness, when the survey took place between 7 and 14 days after the anesthesia, than immediately after the procedure (within 1 day). In our study the questionnaire survey was carried out usually $30 \mathrm{~h}$ after the anesthesia, because of logistic reasons in the hospital.

We found one case of intraoperative awareness, a woman who underwent intravenous anesthesia. This was a 57-year-old woman, in her case an ENT surgery was performed under total intravenous anesthesia. She did not remember any unpleasant feelings, such as fright or pain. The case was qualified as class 2 according to the Michigan Awareness Classification. The patient was informed about the possible consequences of this event and received some advice about the possible psychological support.

The anesthesia protocol of this woman was analyzed. After the induction of anesthesia (T4-T7), because of cardiovascular depression (SAP 90-80 mmHg, HR 40-50/ minute) the level of anesthesia was made shallow; the doses of both remifentanil and propofol were reduced. After a few minutes (T10) the values of recorded clinical parameters quickly increased. The level of anesthesia was deepened, and the rest of the procedure was stable. 
Probably, the patient's memories were derived from this period of anesthesia (T8-T12). In this case the increase of AAI values to 41 (T9) was observed 5 to $7 \mathrm{~min}$ before the reaction of systemic blood pressure and changes in heart rate.

Many authors confirmed, that the higher incidence of such events was noted amongst patients during intravenous anesthesia without intraoperative neuromonitoring ${ }^{52}$. The analysis of the records revealed that during anesthesia an AAI increased to 41; it was an effect of reduced doses of anesthetics in order to decrease the cardiodepression caused by too deep level of anesthesia. During general anesthesia, when the recorded values of AAI are between 30 and 50, there is an increased chance for intraoperative awareness $^{53,54}$. The insufficient level of anesthesia is the most common reason of intraoperative awareness ${ }^{5,20,55,56}$ An analysis of Domino et al. ${ }^{20}$ and Ghoneim et al. ${ }^{5}$ showed that in $15 \%$ to $20 \%$ of cases of known episodes of intraoperative awareness, the simultaneous increase in both systemic blood pressure and heart rate was noted.

An evaluation of the level of anesthesia, based on clinical parameters, is often insufficient for protection of anesthetized patients from intraoperative awareness ${ }^{5,7,20,51}$, especially during intravenous anesthesia. Hence, recommendations of intraoperative neuromonitoring for optimization of the level of intravenous anesthesia, together with continuous, concurrent clinical observation ${ }^{16,24,25}$. Avidan et al. ${ }^{57,58}$ did not found differences in the number of intraoperative awareness between patients who underwent intraoperative neuromonitoring and those under volatile anesthesia, when the level of anesthesia was assessed by the end-tidal concentration of halogenated anesthetics.

Our results suggest that the anesthesia in VOL group was more stable, with AAI values at the lower limits of surgical anesthesia.

Thirteen per cent of participants had dreams under anesthesia, similar in both groups. This corresponds with the literature, where the incidence of dreaming during general anesthesia varies between $1 \%$ and $22 \%$ (ref., ${ }^{7,59,60}$ ). The described patient who had an episode of intraoperative awareness reported no dreams under general anesthesia. In our study, intraoperative dreaming was included in a separate category, not related to intraoperative awareness ${ }^{7,60,61}$; however, some authors believe that their occurrence may result from inadequate level of anesthesia ${ }^{59}$.

Our results are both interesting and clinically useful. However, this study has some limitations. The use of coagulation in the head region may interfere with monitoring of electroencephalography (EEG) and AEP. Moreover, one should realize that in two patients who were monitored in the same way, two distinct readings of AAI values may be received. It can result from complex mechanisms of consciousness, different mode of action of anesthetic drugs, as well as from the genetic diversity of the population. Intraoperative awareness is a devastating, but rare complication.

\section{CONCLUSION}

Clinical monitoring during volatile anesthesia provides adequate protection during surgery. During intravenous anesthesia, the observation of clinical parameters is insufficient for stable maintainance of anesthesia and does not prevent intraoperative awareness. Clinical monitoring itself does not exclude periods of too deep anesthesia. The AAI index is useful tool in monitoring patients' level of consciousness during anesthesia.

\section{ABBREVIATIONS}

AAI, Autoregressive AEP index; AEP, Auditory evoked potentials; ASA, American Society of Anesthesiologists; AWR, Intraoperative awareness; BS, Burst suppression; DAP, Diastolic blood pressure; EEG, Electroencephalography; ENT, Ear, nose and throat; etCO $\mathrm{C}_{2}$ End-tidal concentration of carbon dioxide; $\mathrm{FiO}_{2}$, Fraction of inspired oxygen; MAC, Minimum alveolar concentration; MAP, Mean arterial pressure; PTSD, Posttraumatic stress disorder; SAP, Systolic blood pressure; TIVA, Totally intravenous anesthesia; VOL, Volatile anesthesia.

Author contributions: KS: study design; acquisition and interpretation of data, drafting the work, and its critical revision, final approval; ZR: study design; interpretation of data; drafting the work, and its critical revision; final approval; DT: analysis and interpretation of data; drafting the work, and its critical revision; final approval.

Conflict of interest statement: The authors state that there are no conflicts of interest regarding the publication of this article.

\section{REFERENCES}

1. Saper CB, Chou TC, Scammell TE. The sleep switch: Hypothalamic control of sleep and wakefulness. Trends Neurosci 2001;24:726-31.

2. Vanini G, Baghdoyan HA, Lydic R. Relevance of sleep neurobiology for cognitive neuroscience and anesthesiology. In: Mashour GA, editor. Consciousness, Awareness, and Anesthesia. New York: Cambridge University Press. 2010; p. 1-23.

3. Nelson LE, Guo TZ, Lu J, Saper CB, Franks NP, Maze M. The sedative component of anesthesia is mediated by GABAA receptors in an endogenous sleep pathway. Nat Neurosci 2002;5:979-84.

4. Lu J, Nelson LE, Franks N, Maze M, Chamberlin NL, Saper CB. Role of endogenous sleep-wake and analgesic systems in anesthesia. J Comp Neurol 2008;508:648-62.

5. Ghoneim MM, Block RI, Haffarnan M, Matthews MJ. Awareness during anesthesia: Risk factors, causes and sequelae: A review of reported cases in the literature. Anesth Analg 2009;108:527-35.

6. Wang D-S, Orser BA. Inhibition of learning and memory by general anesthetics. Can J Anaesth 2011;58:167-77.

7. Sebel PS, Bowdle TA, Ghoneim MM, Rampil IJ, Padilla RE, Gan TJ, Domino KB. The incidence of awareness during anesthesia: A multicenter United States study. Anesth Analg 2004;99:833-9.

8. Osterman JE, Hopper J, Heran WJ, Keane TM, van der Kolk BA Awareness under anesthesia and the development of posttraumatic stress disorder. Gen Hosp Psychiatry 2001;23:198-204.

9. Lennmarken C, Bildfors K, Enlund G, Samuelsson P, Sandin R. Victims of awareness. Acta Anaesthesiol Scand 2002;46:229-31. 
10. Samuelsson P, Brudin L, Sandin RH. Late psychological symptoms after awareness among consecutively included surgical patients. Anesthesiology 2007;106:26-32.

11. Leslie K, Chan MT, Myles PS, Forbes A, McCulloch TJ. Posttraumatic stress disorder in aware patients from the b-aware trial. Anesth Analg 2010;110:823-8.

12. Ballard C, Jones E, Gauge N, Aarsland D, Nilsen OB, Saxby BK, Lowery D, Corbett A, Wesnes K, Katsaiti E, Arden J, Amoako D, Prophet N, Purushothaman B, Green D. Optimised anaesthesia to reduce post operative cognitive decline (POCD) in older patients undergoing elective surgery, a randomised controlled trial. PLoS One 2012 7:e37410.

13. Sessler DI, Sigl JC, Kelley SD, Chamoun NG, Manberg PJ, Saager L, Kurz A, Greenwald S. Hospital stay and mortality are increased in patients having a "triple low" of low blood pressure, low bispectral index, and low minimum alveolar concentration of volatile anesthesia. Anesthesiology 2012;116:1195-203.

14. Chan MT, Cheng BC, Lee TM, Gin T, CODA Trial Group. BIS-guided anesthesia decreases postoperative delirium and cognitive decline. J Neurosurg Anesthesiol 2013;25:33-42.

15. Radtke FM, Franck M, Lendner J, Krüger S, Wernecke KD, Spies CD. Monitoring depth of anaesthesia in a randomized trial decreases the rate of postoperative delirium but not postoperative cognitive dysfunction. Br J Anaesth 2013;110(suppl 1):i98-i105.

16. Bischoff $P$, Rundshagen I. Awareness under general anesthesia. Dtsch Arztebl Int 2011;108:1.

17. Ghoneim MM, Block RI. Learning and memory during general anesthesia: An update. Anesthesiology 1997;87:387-410.

18. Schneider G, Sebel PS. Monitoring depth of anaesthesia. Eur J Anaesthesiol 1997;14:21-8.

19. Sebel PS, Lang E, Rampil IJ, White PF, Cork R, Jopling M, Smith NT, Glass PS, Manberg P. A multicenter study of bispectral electroencephalogram analysis for monitoring anesthetic effect. Anesth Analg 1997;84:891-9.

20. Domino KB, Posner KL, Caplan RA, Cheney FW. Awareness during anesthesia A closed claims analysis. Anesthesiology 1999;90:105361.

21. Struys MM, Jensen EW, Smith W, Smith NT, Rampil I, Dumortier FJ, Mestach C, Mortier EP. Performance of the arx-derived auditory evoked potential index as an indicator of anesthetic depth: A com parison with bispectral index and hemodynamic measures during propofol administration. Anesthesiology 2002;96:803-16.

22. Weber F, Seidl M, Bein T. Impact of the aep-monitor/2-derived composite auditory-evoked potential index on propofol consumption and emergence times during total intravenous anaesthesia with propofol and remifentanil in children. Acta Anaesthesiol Scand 2005;49:277-83.

23. Schneider G, Jordan D, Schwarz G, Bischoff PP, Kalkman CJ, Kuppe $H$, Rundshagen I, Omerovic A, Kreuzer M, Stockmanns G, Kochs EF, European Multicenter EEGAEP Anesthesia Monitoring Study Group and Research Group Knowledge-based Signal Processing. Monitoring depth of anesthesia utilizing a combination of electroencephalographic and standard measures. Anesthesiology 2014;120:819-28.

24. American Society of Anesthesiologists Task Force on Intraoperative Awareness. Practice advisory for intraoperative awareness and brain function monitoring: A report by the american society of anesthesiologists task force on intraoperative awareness. Anesthesiology 2006;104:847-64

25. Ziętkiewicz M, Nestorowicz A. Stanowisko Rady Konsultacyjnej Polskiego Towarzystwa Anestezjologii i Intensywnej Terapii ds. Jakości i Bezpieczeństwa Znieczulenia w sprawie niezamierzonych śródoperacyjnych powrotów świadomości. Anestezjol Intens Ter 2012;44:65-71.

26. Liu SL. Effect of bispectral index monitoring on ambulatory anesthesia: A meta-analysis of randomized controlled trial and a cost analysis. Anesthesiology 2004;101:311-5.

27. Freo U, Carron M, Innocente F, Foletto M, Nitti D, Ori C. Effects of A-line Autoregression Index (AAl) monitoring on recovery after sevoflurane anesthesia for bariatric surgery. Obes Surg 2011;21:850-7.

28. de Grood PM, Harbers JB, van Egmond J, Crul JF. Anaesthesia for laparoscopy. A comparison of five techniques including propofol, etomidate, thiopentone and isoflurane. Anaesthesia 1987;42:815-23.

29. Brice DD, Hetherington RR, Utting JE. A simple study of awareness and dreaming during anaesthesia. Br J Anaesth 1970;42:535-42.
30. Mashour GA, Tremper KK, Avidan MS. Protocol for the "Michigan Awareness Control Study": A prospective, randomized, controlled trial comparing electronic alerts based on bispectral index monitoring or minimum alveolar concentration for the prevention of intraoperative awareness. BMC Anesthesiol 2009;9:7

31. Doi M, Gajraj RJ, Mantzaridis H, Kenny GN. Relationship between calculated blood concentration of propofol and electrophysiological variables during emergence from anaesthesia: Comparison of bispectral index, spectral edge frequency, median frequency and auditory evoked potential index. Br J Anaesth 1997;78:180-4.

32. Kurita T, Doi M, Katoh T, Sano H, Sato S, Mantzaridis H, Kenny GN. Auditory evoked potential index predicts the depth of sedation and movement in response to skin incision during sevoflurane anesthesia. Anesthesiology 2001;95:364-70.

33. Kreuer S, Bruhn J, Larsen R, Hoepstein M, Wilhelm W. Comparison of alaris AEP index and bispectral index during propofol-remifentanil anaesthesia. Br J Anaesth 2003;91:336-40.

34. Alpiger S, Helbo-Hansen HS, Vach W, Ording H. Efficacy of the A-line AEP monitor as a tool for predicting acceptable tracheal intubation conditions during sevoflurane anesthesia. Br J Anaesth 2005;94:601-

35. Ekman A, Brudin L, Sandin R. A comparison of bispectral index and rapidly extracted auditory evoked potentials index responses to noxious stimulation during sevoflurane anesthesia. Anesth Analg 2004;99:1141-6.

36. Jeleazcov C, Schneider G, Daunderer M, Scheller B, Schüttler J, Schwilden $\mathrm{H}$. The discriminant power of simultaneous monitoring of spontaneous electroencephalogram and evoked potentials as a predictor of different clinical states of general anesthesia. Anesth Analg 2006;103:894-901.

37. Gajraj RJ, Doi M, Mantzaridis H, Kenny GN. Comparison of bispectral EEG analysis and auditory evoked potentials for monitoring depth of anaesthesia during propofol anaesthesia. Br J Anaesth 1999;82:672-

38. Milne SE, Troy A, Irwin MG, Kenny GN. Relationship between bispectral index, auditory evoked potential index and effect-site EC50 for propofol at two clinical end-points. Br J Anaesth 2003;90:127-31.

39. Nishiyama T, Matsukawa T, Hanaoka K. Is the ARX index a more sensitive indicator of anesthetic depth than the bispectral index during sevoflurane/nitrous oxide anesthesia? Acta Anaesthesiol Scand 2004:48:1028-32.

40. Weber F, Bein T, Hobbhahn J, Taeger K. Evaluation of the alaris auditory evoked potential index as an indicator of anesthetic depth in preschool children during induction of anesthesia with sevoflurane and remifentanil. Anesthesiology 2004;101:294-8.

41. Allahyary E, Zand F, Tabatabaee HR. Evaluation of the adequacy of general anesthesia in cesarean section by auditory evoked potential index: An observational study. Acta Anaesthesiol Taiwan 2008;46:1624.

42. Chen YT, Wang MC, Ooi SJ, Liu CC, Chiang CY, Tsai WK, Chau SW. Comparison of auditory evoked potential index and clinical signs as indicator for laryngeal mask airway insertion. Acta Anaesthesiol Taiwan 2011;49:3-6.

43. Fedorow C, Grocott HP. Cerebral monitoring to optimize outcomes after cardiac surgery. Curr Opin Anaesthesiol 2010;23:89-94.

44. Aranake A, Mashour GA, Avidan MS. Minimum alveolar concentration: Ongoing relevance and clinical utility. Anaesthesia 2013;68:51222

45. Kreuer S, Bruhn J, Larsen R, Bauer C, Wilhelm W. Comparison of BIS and AAI as measures of anaesthetic drug effect during desfluraneremifentanil anaesthesia. Acta Anaesthesiol Scand 2004;48:1168-73.

46. Fahlenkamp AV, Peters D, Biener IA, Billoet C, Apfel CC, Rossaint $\mathrm{R}$, Coburn M. Evaluation of bispectral index and auditory evoked potentials for hypnotic depth monitoring during balanced xenon anaesthesia compared with sevoflurane. Br J Anaesth 2010;105:33441

47. Struys MM, Vereecke $H$, Moerman A, Jensen EW, Verhaeghen D, De Neve N, Dumortier FJ, Mortier EP. Ability of the bispectral index, autoregressive modelling with exogenous input-derived auditory evoked potentials, and predicted propofol concentrations to measure patient responsiveness during anesthesia with propofol and remifentanil. Anesthesiology 2003;99:802-12.

48. Recart A, White PF, Wang A, Gasanova I, Byerly S, Jones SB. Effect of auditory evoked potential index monitoring on anesthetic drug 
requirements and recovery profile after laparoscopic surgery: a clinical utility study. Anesthesiology 2003;99:813-8.

49. Rinaldi S, Consales G, Gallerani E, Ortolani O, De Gaudio AR. A-line autoregression index monitoring to titrate inhalational anaesthesia: Effects on sevoflurane consumption, emergence time and memory. Acta Anaesthesiol Scand 2005;49:692-7.

50. Mashour GA, Kent C, Picton P, et al. Assessment of intraoperative awareness with explicit recall: A comparison of 2 methods. Anesth Analg 2013;116:889-91.

51. Sandin RH, Enlund G, Samuelsson P, Lennmarken C. Awareness during anaesthesia: A prospective case study. Lancet 2000;355:707-11.

52. Mashour GA, Shanks A, Tremper KK, Kheterpal S, Turner CR, Ramachandran SK, Picton P, Schueller C, Morris M, Vandervest JC, Lin $\mathrm{N}$, Avidan MS. Prevention of intraoperative awareness with explicit recall in an unselected surgical population: A randomized comparative effectiveness trial. Anesthesiology 2012;117:717-25.

53. Litvan H, Jensen EW, Maestre ML, Galán J, Campos JM, Fernández JA, Caminal P, Villar Landeira JM. Comparison of an auditory evoked potentials index and a bispectral index versus clinical signs for determining the depth of anesthesia produced by propofol or sevoflurane. Rev Esp Anestesiol Reanim 2000;47:447-57. (in Spanish).

54. Barr G, Anderson RE, Jakobsson JG. A study of bispectral analysis and auditory evoked potential indices during propofol-induced hypnosis in volunteers: The effect of an episode of wakefulness on explicit and implicit memory. Anaesthesia 2001;56:888-93.
55. Errando CL, Sigl JC, Robles M, Calabuig E, García J, Arocas F, Higueras R, Del Rosario E, López D, Peiró CM, Soriano JL, Chaves S, Gil F, GarcíaAguado R. Awareness with recall during general anaesthesia: A prospective observational evaluation of 4001 patients. Br J Anaesth 2008;101:178-85.

56. Ghoneim MM. Awareness during anesthesia. Anesthesiology 2000;92:597-602.

57. Avidan MS, Jacobsohn E, Glick D, Burnside BA, Zhang L, Villafranca A, Karl L, Kamal S, Torres B, O'Connor M, Evers AS, Gradwohl S, Lin N, Palanca BJ, Mashour GA; BAG-RECALL Research Group. Prevention of intraoperative awareness in a high-risk surgical population. $\mathrm{N} \mathrm{Engl}$ J Med 2011; 365: 591-600.

58. Avidan MS, Zhang L, Burnside BA, Finkel KJ, Searleman AC, Saager L, Turner MS, Rao S, Bottros M, Hantler C, Jacobsohn E, Evers AS. Anesthesia awareness and the bispectral index. N Engl J Med 2008;358:1097-108.

59. Samuelsson P, Brudin L, Sandin RH. Intraoperative dreams reported after general anaesthesia are not early interpretations of delayed awareness. Acta Anaesthesiol Scand 2008;52:805-9.

60. Leslie K, Skrzypek H, Paech MJ, Kurowski I, Whybrow T. Dreaming during anesthesia and anesthetic depth in elective surgery patients: a prospective cohort study. Anesthesiology 2007;106:33-42.

61. Ghoneim MM, Block RI, Dhanaraj VJ, Todd MM, Choi WW, Brown CK. Auditory evoked responses and learning and awareness during general anesthesia. Acta Anaesthesiol Scand 2000;44:133-43. 